\title{
An Electric Hydraulic Driving System of Lifting Platform for Composite Roller Casting
}

\author{
Yongling Fu, Pengfei Zhang
}

School of mechanical engineering and automation, Beihang University, Beijing, 100191, China

Keywords: lifting platform, electric hydraulic driving system, long stroke, composite roller casting, AMESim

\begin{abstract}
To solve the engineering problem that the present driving system of lifting platform for composite roller casting works with high failure rate, this paper has analyzed the cause of the failure, summarized all kinds of popular driving system of lifting platform, designed a set of proportional valve controlled electric hydraulic driving system, and tested its performance in hydraulic modeling and simulating software AMESim. Results show that the performance of the designed system is good enough to meet the present technical requirements. The design of the driving system is also a reference for other lifting platform with long stroke, heavy load and high accuracy.
\end{abstract}

\section{Introduction}

In mining and metallurgy industry there is a huge consumption in wear-resistant parts while many components fail due to wear and tear. If wear-resistant parts like roller, jaw plate and hammer were made entirely with high hardness materials, the cost would be huge and the processing of nonworking surface would be difficult, thus double metal composite material is needed, i.e. materials of high hardness are used in working surface while materials of high toughness are used in nonworking surface, which reduces cost and improves performance. The main methods of double metal compositing include solid-solid compositing, liquid-solid compositing and liquid-liquid compositing, and commonly used techniques of composite roller casting include Jet-casting method, Continuous casting method, Electro slag smelting casting method, Inserting casting method, Centrifugal casting method and so on[1]. Dafang Industry Corporation, the provider of this project, takes Continuous casting method to cast rollers.

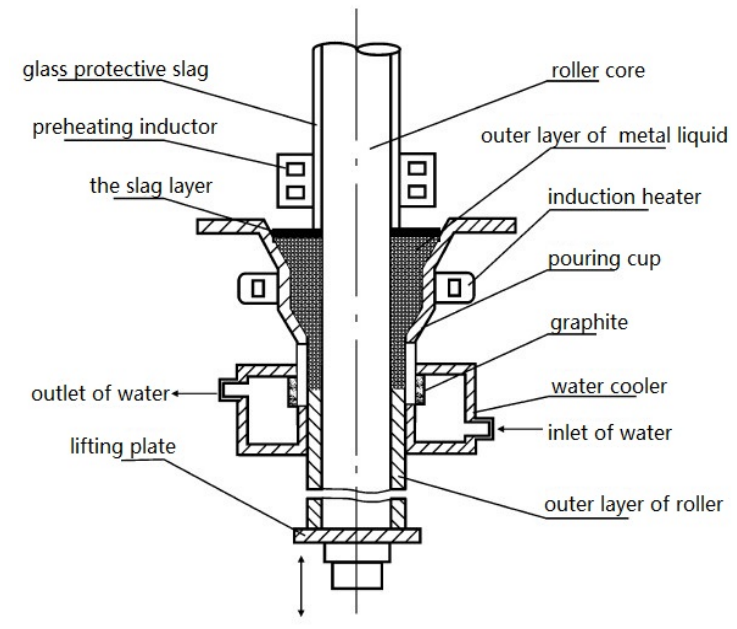

Fig 1.1 Continuous casting method

In Continuous casting method to cast rollers, first the outer layer of metal liquid should be poured into the mold to blend with roller core which was preset in the mold, then pull the roller core down in a predetermined speed to make outer layer of metal liquid composite with roller core, thus a composite roller is made. To make outer layer of metal fully merged with roller core, Electromagnetic induction heating method is used to heat metal liquid and roller core. Fig1.1 shows the basic structure of Continuous casting method. Dafang Industry Corporation has made a variety of double-metal composite rollers using this method. The composite rollers made by this method have excellent mechanical properties, great high-temperature performance and good microstructure, 
thus rollers could be casted instead of be forged. Besides, this method can be used not only to make new rollers but also to repair old rollers, which has great economic potential.
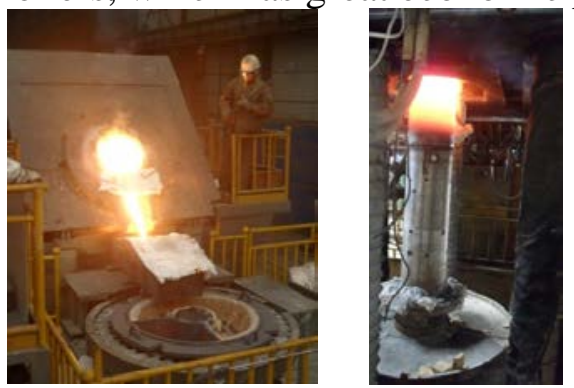

Fig1.2 Cast rollers on site

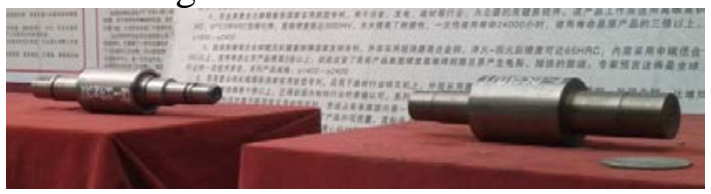

Fig1.3 Composite rollers

But there is a big problem in the present driving system of lifting platform. The present driving system takes use of screw nut mechanisms which are symmetrically set vertical to the unbalanced loads. Because of bad working condition, severe pollution, strong thermal shock, heavy load unbalanced and drive error of screw nut itself, the device works with high failure rate, and repair and replacement of elements costs a lot of time which heavily influences production efficiency, thus the present driving system is in urgent need of improvement. Technical qualifications are shown in Table1.1. As is seen, the main features of this platform are the heavy load, long stroke, require of high accuracy, and adaptability to bad working condition.

Table1-1 Technical qualifications of lifting platform

\begin{tabular}{|c|c|}
\hline Index terms & Parameters \\
\hline Total mass of loads & $20 \mathrm{t}$ \\
\hline up-going load & 20t, downward \\
\hline down-going load & less than $20 \mathrm{t}$, downward \\
\hline working stroke & $4500 \mathrm{~mm}$ \\
\hline working speed (vertical downward) & $\begin{array}{c}5 \mathrm{~mm} / \mathrm{s}-10 \mathrm{~mm} / \mathrm{s}, \text { with } \\
\text { stepless speed regulation }\end{array}$ \\
\hline no-load speed (vertical upward) & $\begin{array}{c}\text { maximum30mm/s, with } \\
\text { stepless speed regulation }\end{array}$ \\
\hline accuracy of speed & $0.5 \mathrm{~mm} / \mathrm{s}$ \\
\hline working frequency & $10,000 \mathrm{times} / \mathrm{year}$ \\
\hline working condition & $-20^{\circ} \mathrm{C}-300^{\circ} \mathrm{C}$ \\
\hline response time of starting and braking & $<0.5 \mathrm{~s}$ \\
\hline
\end{tabular}

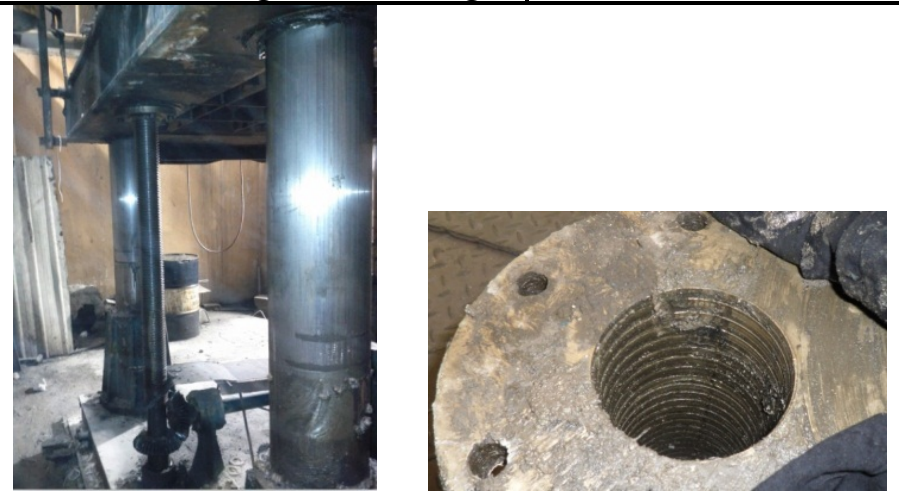

Fig1.4 the present screw-nut lifting driving system and the worn-out nut 


\section{A summary of driving system of lifting platforms}

As a kind of lifting equipment, lifting platforms are widely used in logistics, transportation, assembly, parking, offshore oil field and many other working conditions. The main function of lifting platforms is lifting different loads to certain height by driving system and lifting mechanisms. Lifting mechanisms could be divided into 3 kinds by characteristic of rigidity and flexibility: rigid lifting mechanisms, flexible lifting mechanisms and rigid-flexible lifting mechanisms. Rigid lifting mechanisms include pinion and rack, plunger mechanism, scissors mechanism, screw mechanism and so on in which pinion and rack has a simple form and high accuracy while it's expensive and hard to make, and traditional plunger mechanism can lift heavy load while has bad accuracy, and scissors mechanism can also lift heavy load and has a compact structure which makes it easy to stretch and fold while it's hard for speed control especially for uniform speed control, and screw mechanism has high accuracy and compact structure while it can hardly bear dirty condition or thermal shock. Flexible lifting mechanisms include wire rope mechanism and chain mechanism in which wire rope mechanism has simple form but it has bad accuracy and stability, and chain mechanism is also simple-formed and cheap but it has bad accuracy and stability too. Rigid-flexible lifting mechanisms are new forms and showed up lately which is rigid when working and flexible when not working which have distinct advantages in terms of installation space while the structure is complicated and accuracy is not good enough[2].

\section{Design of electric hydraulic driving system}

Considering the working condition, this paper has designed a set of proportional valve controlled electric hydraulic driving system based on technical qualifications which are symmetrically set parallel to the unbalanced loads. Fig2.1 shows its hydraulic schematic diagram.

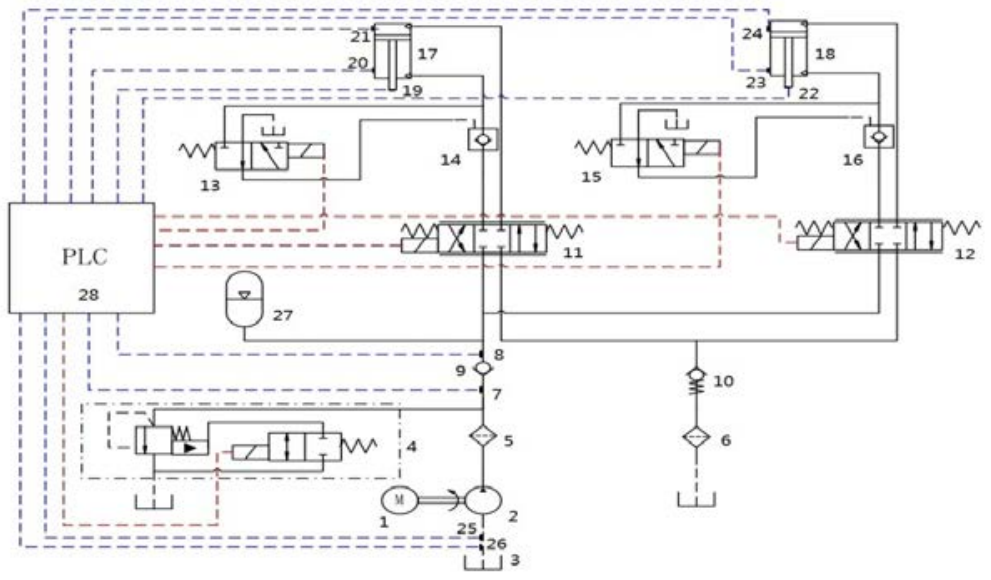

Fig2.1 hydraulic schematic diagram of this design

1. constant speed motor; 2.constant rate pump; 3.hydraulic tank; 4. overflow valvewith solenoid switch unloading; 5.inlet filter; 6.outlet filter; 7.pressure sensor in main oil-way; 8.relay; 9.check valve; 10.check valve with backpressure; 11.12.proportional and directional valve; 13.15 .directional valve; 14.16.hydraulic controlled check valve; 17.18.hydraulic cylinder; 19.22.displacement sensor;

20.21.23.24.pressure sensor; 25.hydraulic level sensor; 26.temperature sensor; 27.accumulator; 28.PLC controller

The system consists of two symmetric channels. Because of symmetric unbalanced loads, the two channels are designed symmetrically, installed symmetrically and controlled symmetrically, which brings little error and high accuracy. The basic controlling method of the system is to regulate flow by controlling the opening degree of proportional and directional valve, thus to control the moving speed of piston rod or the platform [3].

Hydraulic cylinder 17 and 18 is customized with long stroke and huge output. The cylinder is attached to the upper platform through a trunnion, and the piston rod is hinged with the moving platform, thus making the loads straight downward. Based on design methods of long-stroke pullrod type hydraulic cylinder and the load of $20 \mathrm{t}$, the pressure of the system is set $21 \mathrm{MPa}$, and the 
diameter of piston rod is set $140 \mathrm{~mm}$, piston $186 \mathrm{~mm}$, external diameter of the cylinder $220 \mathrm{~mm}$ and the stroke $4500 \mathrm{~mm}$ after technical round off calculation.

Constant speed motor 1 is attached to constant rate pump 2 through coupling to supply the system fluid and pressure. Filter 5 and 6 are set respectively at inlet and outlet, wherein filter 5 is a refined one and filter 6 is a coarse one, which inhibits pollution of the hydraulic system and kind of cools the system. Overflow valve 4 with solenoid can switch unloading, which makes the system unload while power on and keeps the pressure on while power off. Check valve 9 makes sure the flow of the system in one direction thus keeping the lifting platform from sliding down because of gravity. Accumulator 27 supplies extra fluid for the hydraulic system, thus making the system pressure not less than of itself and preventing occurring of cavitations. Meanwhile, the accumulator can absorb pressure impact. Check valve 10 keeps the system a certain backpressure, thus preventing air to flow in. Proportional and directional valve 11 and 12 are key components of the design, which regulate flow by controlling the opening degree of valve based on control signal, thus to control the moving speed of piston rod. Hydraulic controlled check valve 14 and 16 are controlled by directional valve 13 and 15, which stay bi-directional open when directional valve is conducted while stay one-direction open when the directional valve is electrical off, thus making sure that the platform would not slide down because of gravity when the system is power off.

The controller is chosen S7-200 PLC, which is in charge of acquisition and monitoring of signals. As for the speed control, the method is to control the opening degree of proportional and directional valve based on feedback speed signal, a differential displacement signal which is measured by displacement sensor.

\section{Modeling and simulation analysis based on AMESim}

LMS Imagine. Lab AMESim (Advanced Modeling Environment for performing Simulation of engineering systems) is a modeling and simulation platform for multidisciplinary and complicated systems. Users can build up complex multi-field models on this single platform, and carry out simulating calculation and deeper analysis based on the models, as well as analyze steady-state and dynamic performance of components or the system. This platform has been used in fuel injection, braking system, power system, hydraulic system, mechanical and electrical system, cooling system and so on.

Based on hydraulic schematic diagram of this design, a single-channel mode is set up in AMESim as shows in Fig2.2.

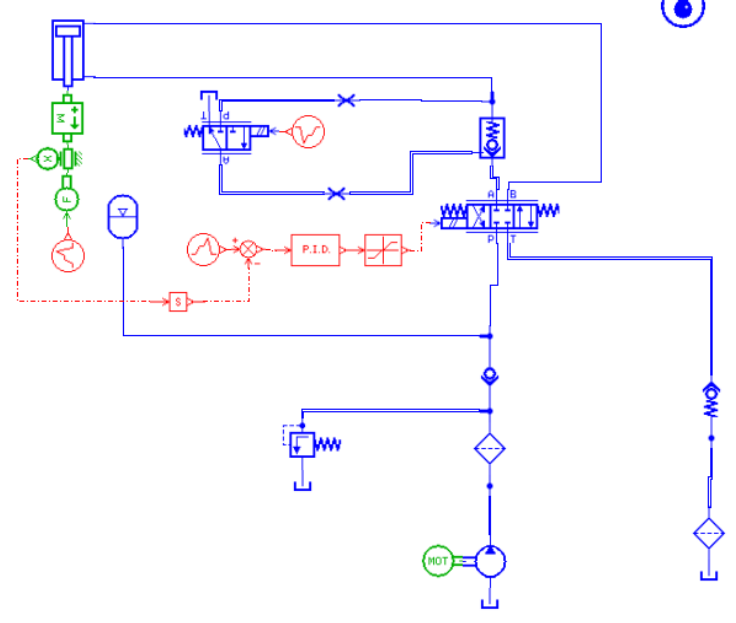

Fig2.2 single-channel mode for simulation

This mode consists of hydraulic part and control part. The proportional valve is the heart of the hydraulic part. The speed of the cylinder can be controlled by controlling the open degree of the valve. The load of cylinder is presented as a 20t mass and a $200 \mathrm{KN}$ downward force. Other hydraulic attachments include check valve, accumulator, filter, overflow valve and so on. The control part uses the strategy of speed feedback closed-loop control which compares the speed 
signal, measured by displacement sensor and differenced, and the input target speed signal, and uses the error which is processed by a PID processor to control the opening degree of the proportional valve, thus to control the speed of the piston rod. Parameters of the simulation system are shown in Table 2-1.

Table 2-1 Parameters of the simulation system

\begin{tabular}{|l|l|l|}
\hline Parameters & Value & Unit \\
\hline Speed of motor & 3000 & $\mathrm{Rev} / \mathrm{min}$ \\
\hline Output rate of pump & 20 & $\mathrm{cc} / \mathrm{min}$ \\
\hline Pressure of accumulator & 210 & $\mathrm{bar}$ \\
\hline Volume of accumulator & 10 & $\mathrm{~L}$ \\
\hline $\begin{array}{l}\text { Setting pressure of overflow } \\
\text { valve }\end{array}$ & 280 & $\mathrm{bar}$ \\
\hline $\begin{array}{l}\text { Maximum flow rate of overflow } \\
\text { valve }\end{array}$ & 60 & $\mathrm{~L} / \mathrm{min}$ \\
\hline $\begin{array}{l}\text { Opening pressure of back } \\
\text { pressure check valve }\end{array}$ & 10 & $\mathrm{bar}$ \\
\hline $\begin{array}{l}\text { Maximum flow rate of } \\
\text { proportional valve }\end{array}$ & 80 & $\mathrm{~L} / \mathrm{min}$ \\
\hline $\begin{array}{l}\text { Controlling current of } \\
\text { proportional valve }\end{array}$ & 20 & $\mathrm{~mA}$ \\
\hline $\begin{array}{l}\text { Responding frequency of } \\
\text { proportional valve }\end{array}$ & 80 & $\mathrm{~Hz}$ \\
\hline $\begin{array}{l}\text { Opening pressure of check } \\
\text { valve }\end{array}$ & 3 & $\mathrm{bar}$ \\
\hline Mass of platform & 20 & $\mathrm{t}$ \\
\hline Stroke of hydraulic cylinder & 4500 & $\mathrm{~mm}$ \\
\hline Diameter of piston & 186 & $\mathrm{~mm}$ \\
\hline Diameter of piston rod & 140 & $\mathrm{~mm}$ \\
\hline Kp & 1000 & $\mathrm{null}$ \\
\hline Ki & 10000 & $\mathrm{null}$ \\
\hline Kd & 50 & $\mathrm{null}$ \\
\hline
\end{tabular}

Set simulation total time at $6 \mathrm{~s}$, simulation step time at $0.001 \mathrm{~s}$, and the results are shown below.

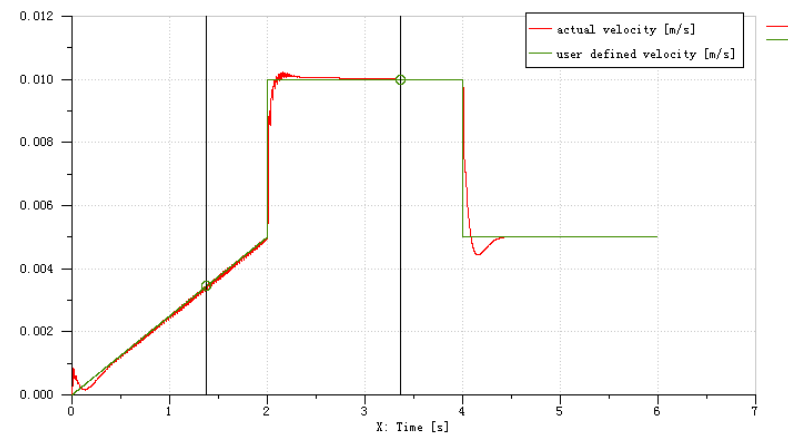

Fig2.3 Performance of system while working downward 


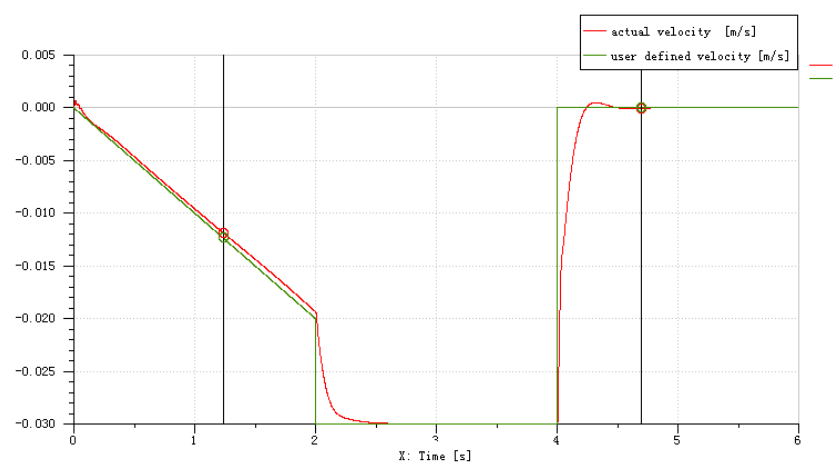

Fig2.4 Performance of system while working upward with no load

Fig2.3 shows the performance of platform while working downward. The input target signal in $0 \sim 2 \mathrm{~s}$ is a ramp signal which represents stepless speed regulation, in $2 \sim 4 \mathrm{~s}$ is a $10 \mathrm{~mm} / \mathrm{s}$ constant speed signal which represents maximum speed of casting, and in $4 \sim 6 \mathrm{~s}$ is a $5 \mathrm{~mm} / \mathrm{s}$ constant speed signal which represents minimum speed of casting. As showing in results, actual accuracy of speed is higher than $0.5 \mathrm{~mm} / \mathrm{s}$ and the responding time is less than $0.5 \mathrm{~s}$, the speed is steady and the responding is rapid, and the technical qualifications of lifting platform are satisfied.

Fig2.4 shows the performance of platform while working upward which is no-load returning. The input target signal in 0 2s is a ramp signal which represents stepless speed regulation, in 2 4s is a $-30 \mathrm{~mm} / \mathrm{s}$ speed signal which represents maximum speed of no-load returning process, 4 6s is a constant zero speed signal while hydraulic controlled check valve is powered off which represents the stop of lifting platform and the locking performance of it when power off. As the result shows, actual accuracy of speed is high than $0.5 \mathrm{~mm} / \mathrm{s}$ and the responding time is less than $0.5 \mathrm{~s}$, the speed is steady, the responding is rapid, the locking performance is good, and the technical qualifications of lifting platform are satisfied.

\section{Conclusion}

In this paper, an electrical hydraulic driving system with long stroke and high accuracy is designed to satisfy the technical need of a lifting platform used in composite roller casting. As the simulation result shows, the designed proportional valve controlled electric hydraulic driving system has good dynamic performance and can satisfy the technical qualifications of lifting platform, which is very suitable for this working condition. The design of the driving system is also a reference for other lifting platform with long stroke, heavy load and high accuracy.

\section{References}

[1] Jiangwei Shi, Dixin Yang, Feng Ni, Rui Long. Progress of high speed steel composite casting[J]. Research Studies on Foundry Equipment, 2005.01

[2] Gan Du. Research status on driving system of lifting platform[J]. Mechanical engineering and automation, 2013.04

[3] Chunxing Wang. Hydraulic control system, Mechanical Industry Press, 2008

[4] Haitao Qi, Yongling Fu. Simulation analysis of EHA based on AMESim. Machine and Hydraumatic, 2007.03 